\title{
Mindset development by applying $U$ theory and religious concept in educational system: Thailand as a case
}

\author{
Kannapat Kankaew, ${ }^{1, *}$ \\ ${ }^{1}$ International College; Suan Sunandha Rajabhat University, Thailand
}

\begin{abstract}
The dynamic changes, the fast growing of technology, causing unpredictable environment that forces people to live with tension. Man must learn to adapt oneself mentally to the changing phenomenal. The mindset is crucial for a workplace and chaotic society. This article, the author has reviewed religious concept and the $U$ theory form secondary data. The purpose is to propose the development of people emphasis on their mindset by employing the alignment of the two concepts in the educational system in Thailand. These two concepts accent to cultivate in the deepest mind of human. It enhances people to have consciousness, being an open mind, open heart, and open will. As a result, making people to live with others harmoniously, peacefully, seeing things as it is, and aware of their thought and temper that might lead to intolerable situations.
\end{abstract}

\section{Introduction}

Presently, the modern globalization become more complex since it evolves by the mean of economic using monetary to open free trade, investing and funding. The developed countries have better capability and knowledge of business competitiveness. Moreover, they have good economy which lead to purchasing power in the perfect market [1]. Furthermore, the advancement of technology makes the globe become flat where people are freely getting in touch both face to face and remote. Whereas, the robotics or artificial intelligence $(\mathrm{AI})$ are replacing repetitive workforces.

As a result, various types of firms adapt their business model by reducing workforce or shutting down their branches. People, as well as, needs to re-skills, up-skills and practice life-long learning to create their own value, where AI could not replace. Those who are fail to improve themselves may face with difficulties to live in the fast-changing environment. People reacts to the problem and tension differently; some might express aggressively while others might suffer from depression.

Thus, in Thailand the government has implemented the policy to develop human capital to be ready for the unforeseen changes of the future. However, no one knows the right skills set necessary for the future, unless the mindset of people who willing to be a life-long learner and know how to adapt themselves to the dynamic of changes. This is consistent to

* Corresponding author: kunnapat.ka@,ssru.ac.th 
[2] suggested that the workforce should be educated to be able to learn and grow focus on developing attitudes and behaviour. Since the mind leads to action whether positive or negative. A person who lack of consciousness or education might conduct objectionable, such as teenagers replicate the risky, threatening, or violent behaviour from social media. Therefore, the author aims to highlight the $U$ theory and religious concept (in this article refers to Buddhism) which instruct people from the deepest of mind, spending a moment to feel and noticing their own mental state. So that people could control their actions and conduct their behaviour properly.

\section{Theoretical and analysis}

In the disruptive paradigm of changes, the high quality of education alone is not enough for harmonious society. The good quality populations shall have good health, knowledge, skills, and specifically morals and ethics $[3,4,5]$. Nevertheless, the action of human depends on the value, perception, attitude, and personality they hold with them. The value is the believe, attitude, norms which lead to action and practice [6].

To develop human in Buddhism called Sikkhā or education. Prior to administer the education to human, one must understand the human behavior. In Buddhism divided human behavior or actions called karma into three types including; physical actions, actions derive from verbal, and the thought. These three kinds of actions the thought is the most influential for human to be, to act. Therefrom, the education in Buddhism highlights on human mind to be neutral to whatever they sensing from the five sense of touches. Those are seeing, hearing, smelling, touching and tasting.

These five senses of touches might generate favorable or unfavorable feeling, such as one experiences something amicable, one would be happy. In contrast, if one experiences something rough, he/she would be agitated. The mood of human is also contagious to each other's. It is worth noticing that if you stay close to someone having bad mood, you would also be feeling unhappy. Furthermore, whatever actions one commit, the result would reflect to he/she in any kind. On the ground, to educate people in Buddhism stress profoundly on the mind which will lead to improve human behavior, intellectual, and mind $[7,8]$.

From the reason of human is a social being [1] proposed that the whole world can live peacefully together as a concept of new normal of imagination. He considers that imagination come before knowledge, man can imagine without boundary as one wishes. And certainly, the imagination is a power to construct knowledge. All human being and all form of life are living in the same world or 'the same oneness'. If something was demolished, others would be affected and ruining. Correspondingly, human will lose harmonious. In fact, human has spirituality to survive by nature just as when we sacrifice or help other people the endorphin of happiness will be released. This endorphin would generate spiritual happiness, which make human become healthier. If a person lost spiritual happiness, that person would lack of self-actualization and will searching for it. The society system is diverse, but must be an integrity of diversity. By considering of three dimensions including; firstly, expanding the spiritual relatedness from community, social and the world.

Secondly, building the social fundamental structure like the body's cell that connected and work systematically. And thirdly, construction of the communication system as a whole i.e. all people knowing the same facts. In the new paradigm of human being, it is a must to create a cognitive of holistic view of individual to be the wholeness. Everyone has to understand the reality of environment that everything is dynamic inter-connected. It is a new consciousness since each individual at different life stage has distinctive consciousness 
of mind. The harmonious of mind will let us free from defilements and stimulate universal love, understanding to others and any being.

Whereas theory $U$ proposed by [9] explained that the theory explores to disseminate a hidden dimension of social process that human confront every day. The theory as a new science to performed with the mind of enlightenment. Albeit, the purpose of theory $U$ is suitable for leaders and individuals or groups to handle with fluctuate situation by inner source of innovation. The $\mathrm{U}$ will penetrate into cognitive spaces profoundly for innovation and changes. The theory clarifies the journey of innovation to shine out from observing, reflecting, plan and act. One shall have a freedom of mind to stress on the senses, observe, perceive of any queries arise as an initiative. It starts from downloading information and seeing by holding the judgement; after that sensing the whole situation and observe until it fades away, then it goes to presencing which means one can connect to the deepest source within, and later it is crystallizing vision that emerge.

The last two steps are prototyping to explore the future by doing the new thought, and performing the newness into practices. The $U$ theory also influenced by [10] that creativity is important for health, happiness and all aspect of life succeed. The creativity is inside everyone, but it was covered by the voice of judgement. To let the creativity come out, one need suspension with patience and willingness not to conceptualize framework on what one sees, rather observe without forming conclusion. Even, the group dynamic has coercive share of norms and ways of thought, seeing effectively, but people have to learn how to take time, assess, and stop assumption. There are two types of knowing, one is 'analytic knowing' and 'primary knowing'.

The analytic knowing is a cognitive science compose of independent objects and the state of human mind. By far majority, human live analytic knowing segregating "I" and "it". In contrary to primary knowing, it is an interconnected wholeness, no isolation, direct, presentation, spontaneous by means of timeless and larger than the 'self'. So the scholars present the model $\mathrm{U}$ starting from sensing, presencing, and realizing as shown in figure 1.

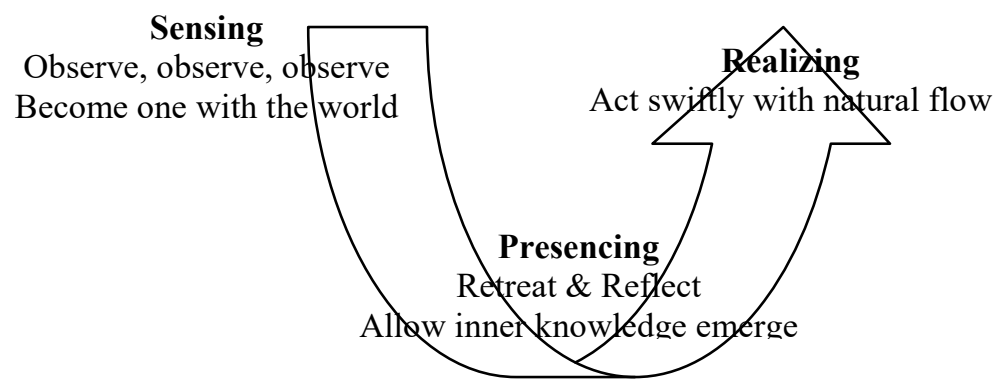

Fig. 1. Sensing

In addition, [10] explains that individual must open mind, open heart, and open will. These three words can be explained that the open mind is the ability to access intellectual (IQ). The open heart is the capability to reach an emotional intelligence (EQ), which means the competence to empathize others in different context. And the open will is the ability to reach an authentic aim or spiritual intelligence (SQ). For this reason, the author sees that institutions can adapt to learning and teaching for Thai students, notably in the deepest mind and consciousness. 


\section{Conclusion and recommendations}

In conclusion, the education in Buddhism cultivates people profoundly from inside out at the consciousness level of mindfulness to behave morally and ethically. It is to make people aware of their own actions. In the essence is that to be ignorance to any kind of defilement, agitation, but just observe that feeling and soon it will fade away. The conscious mind would also bring insightful knowledge. It is the new knowledge, thereto, might be come up for solving the problem which quite necessary for knowledge-based economy in the disruptive environment.

At this time, most of institutions practice knowledge management searching for best practice to use in learning, teaching, research and innovation. Therefore, the concept of developing from the deeper level of mind should be consider to use for teaching and learning. As it would be beneficial for people to understand others, and feeling the wholeness. While, the $U$ theory is to compliment by instructing people to avoid using their experience to judge without cogitate. In the same notion, these two theory guidelines people to use their analytical thinking skills, logical skills, and problem-solving skills effectively. Therefore, in the chaos and disruptive era the consciousness and mindset development shall be cultivate for young generation throughout the country via the educational system.

\section{References}

1. P. Wasee, The human life in 21st century: new normal of development (2002)

2. A. Lundberg., G. Westerman, The transformer CLO (2002). http://www.hbr.org

3. B. Dokthaisong, Human capital management (2008)

4. B. Hunchangsith, Economics of human resources (3rd ed.) (2006)

5. G. S. Becker, Human capital : a theoretical and empirical analysis (1993)

6. C. Wichuda, Human relations and personality development (2009)

7. P. Payutto, The characteristic of Buddhism (2010)

8. P. Payutto, The concept of Buddhism (2004)

9. O. C. Scharmer, Theory U : leading from the future as ite merges (2009)

10. P. Senger., O. C. Scharmer., J. Jaworski., B. S. Flowers, Presence: human purpose and the field of the future (2004) 